\title{
Physiological Electromyographic Activations Patterns of Lower Limb Muscle in Children
}

\author{
Maria Grazia Benedetti ${ }^{*}, 1$, Valentina Agostini ${ }^{2}$, Giulia D’Apote ${ }^{1}$ and Marco Knaflitz ${ }^{2}$ \\ ${ }^{I}$ Movement Analysis Laboratory, Istituto Ortopedico Rizzoli, Bologna Italy \\ ${ }^{2}$ Dipartimento di Elettronica, Politecnico di Torino, Torino, Italy
}

\begin{abstract}
Kinesiological electromyography (KEMG) is an essential part of gait analysis as it supports clinicians with the objective assessment of muscular function during walking. During the gait cycle muscles are active with definite actions aimed at controlling joints in order to accomplish requirements of gait such as stability, loading acceptance, and progression. The knowledge of the development of normal EMG activity is of relevance in interpreting gait analysis data. While there is a wide literature on normative kinematics and kinetics data in children, only a few studies reported reference KEMG dataset on a paediatric population and on the maturation of gait in children. The available literature reported that the surface KEMG in children has a significant amount of variability, which should be taken into consideration when performing clinical interpretations. The KEMG timing and duration in normal children can vary with age, body height, body weight, gait velocity and stride length. Moreover, there is evidence that within session EMG variability in children aged 6-8 years is twice than that of adults. Although children in this age range can be considered to have a mature walk, variability about the mean performance continues to develop for many years and stable locomotion may be achieved despite significant variability in the muscle recruitment patterns. Further studies using accurate techniques of signal detection and analysis are required to improve our knowledge on physiological and pathological patterns of muscular activation in children.
\end{abstract}

Keywords: Muscle, surface electromyography, lower limbs, children, gait.

\section{INTRODUCTION}

Kinesiological electromyography (KEMG) is an essential part of gait analysis as it supports clinicians with the objective assessment of muscular function during walking. Especially when associated with dynamic of gait, it provides insight on biomechanics of walking and on neural control during walking $[1,2]$. There is wide evidence on its role in clinical diagnosis making in Cerebral Palsy [3] as well as in stroke patients [4].

While there is a wide literature on normative KEMG data in adults [5-7] only a few studies reported reference KEMG datasets on a paediatric population [8-10], and particularly on changes depending on the maturation of gait in children $[11,12]$. In paediatrics, in fact, there is a significant change in body size and neurological function during development that could affect the KEMG activity [8]. Actually, in most cases, data provided by Perry [5] in adults are still the only reference most clinicians take into account for children.

A few works are devoted to the analysis of KEMG pattern changes induced by speed of progression $[9,10,13]$. As most disabled children walk with reduced speed, it is very important to differentiate EMG modifications induced by speed of progression from those due to pathology [10].

*Address correspondence to this author at the Movement Analysis Laboratory, Istituto Ortopedico Rizzoli, Via di Barbiano 1/10, 40136 Bologna, Italy; Tel: +390516366529; Fax: +390516366561;

E-mail: benedetti@ior.it
During the gait cycle, muscles are active with definite actions (Fig. 1) aimed at controlling joints in order to accomplish requirements of gait such as stability, loading acceptance, and progression on support foot and, as overall function, energy conservation [5]. The biomechanics of normal gait has been extensively treated in fundamental books $[5,6,14]$ to which we refer the readers for further insight in this topic. The aim of this work is to review literature on the effects of age and speed of progression on the EMG signal.

\section{EMG PATTERN AND AGE}

The knowledge of the development of normal EMG activity in children is of relevance in interpreting abnormal changes seen in the diagnostic gait analysis laboratory. One of the early works reporting age related surface EMG timing of activation in children was that one of Sutherland [11]. With increasing age, Sutherland found that the Gluteus Maximus showed a slight trend toward shortening of the activation time during stance phase as well as the Vastus Medialis which showed a reduction in the time of activity during both stance phase and swing phase, while the Tibialis Anterior showed a gradual reduction in the time of activation during stance phase. Both the Medial and Lateral Hamstrings of children showed prolonged stance-phase activity compared with adults, but the activity gradually decreased with increasing age. No change with age was observed in Gluteus Medius activity. In particular, Sutherland evidenced that the Gastrocnemius-Soleus complex showed a pattern of activity age related. While a normal adult phasic activity was present from two up to seven years old children (mature 

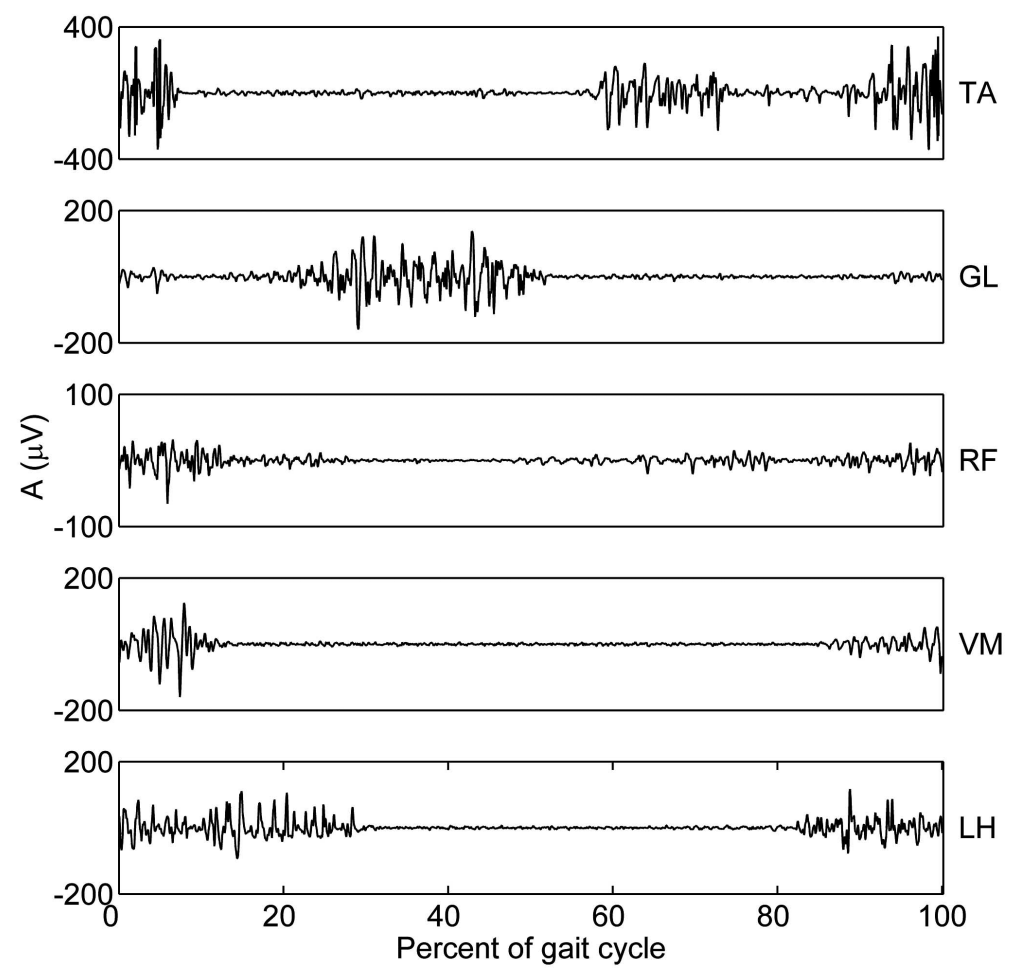

Fig. (1). Example of muscle activity (raw EMG signals) of a child 10 years old recorded during a gait cycle. Muscles explored with surface EMG were Tibialis Anterior (TA), Gastrocnemius Lateralis (GL), Rectus Femoris (RF), Vastus Medialis (VM) and Lateral Hamstrings (LH). Signals were acquired using single differential probes constituted by Ag-disks (diameter: $4 \mathrm{~mm}$, interelectrode distance: $12 \mathrm{~mm}$, gain: 1000 , high-pass filter: $10 \mathrm{~Hz}, 2$ poles). EMG signals were further amplified and low-pass filtered by the recording system (450 Hz, 6 poles).

pattern), high activity was very common in late swing-phase and initial stance-phase in very young children (1-1.5 years old, immature pattern), and it was present in approximately one quarter of the subjects in the remaining age-groups. Complexity of movement which requires long time of development, the sequence of myelination as a component in the maturation process and the level of motor innervations in the spinal cord are the three hypotheses Sutherland provided to explain immature gait pattern [11].

The effects of age on EMG patterns during walking in children were studied also by Shiavi et al. [9]. Results demonstrated that, in an age span of 4-11 years, only the Rectus Femoris and the Hamstrings showed significant agerelated changes.

In a more recent paper, Chang et al. [8] did not confirm the dual pattern of Gastrocnemius-Soleus activity in children, and concluded that the pattern of muscle electrical activity recorded in normal children was not found particularly different from that recorded previously in adults. In normal subjects assessed in the Chang's study however nearly $13 \%$ of the curves were not functionally interpretable as having physiological patterns. This variability was supposed to be related to many conditions specific to the testing situation, such as the position of electrodes, interelectrode distances, skin temperature, electrode contact with the skin, and electrode-wire connection, as well as conditions specific to the subject, such as fiber type, thickness of subcutaneous fat, muscle cross talk, and muscle recruitment patterns. The effects of these subject-specific and situation-specific conditions, associated to the possible effects of signal processing $[15,16]$, are often out of the control of the examiner, and can adversely influence the final signal detection. The surface KEMG in children had in conclusion a certain variability, which has to be taken into consideration for clinical decision making. There is further evidence that within session EMG variability in children aged 6-8 years is twice than that of adults. Although children in this age range can be considered to have a mature walk [11], Granata et al. [17] hypothesize that variability about the mean performance continues to develop for many years and stable locomotion may be achieved despite significant variability in the muscle recruitment patterns. Variability in children may indicate a stabilizing control even more responsive than in adults, supporting the hypothesis that a young neurocontrol system can operate on more degrees of freedom. In this respect, another EMG study can be enlightening [12]. It was carried out on a girl from 3 weeks after birth until 7 years of age to determine EMG changes in the development of human bipedal locomotion. Findings from this original study confirmed changes during the first three years of life from the neonatal stepping to the mature walking, characterized by gross patterns of muscle activation during walking, frequently including co-activation of mutual antagonists. A progression from excessive gross activation to more efficient and economical production of muscle activities in the lower limbs was observed not only in supported walking and then in subsequent independent walking, but also in neonatal primitive walking. The authors suggested that the refinement of excessive co-activation, indicating an increased level of skill in human locomotion, is related to changing posture by improvement of strength and balance control related to the maturation of the central nervous system. These results are also confirmed by the 
study of Detrembleur [10] on the activity of Tibialis Anterior, Triceps Surae and Peroneus Longus which resulted independent from age in the 4 to 11 years interval.

\section{EMG PATTERN AND GAIT SPEED}

The variability of muscular timing during gait has been explained, in adults, in terms of effect of speed variation and inter-subjects variability $[5,7,16]$. The effects of velocity on EMG patterns during walking in children were studied by Shiavi et al. [9] both in terms of relative intensity of existing phases of activity and of appearance of additional phases of activity. At lower speeds it was found that the muscle's pattern were much more individualized while a trend of linear envelopes towards more consistent patterns in terms of increased amplitude of the phases of activity was reported as speed increased. This was particularly evident for Tibialis Anterior, Medial Gastrocnemius, Soleus and Peroneus Longus. A variability in terms of number of activation phases (monophasic, biphasic or triphasic) was observed in Lateral Hamstrings, Tibialis Posterior and Rectus Femoris. This behavior is however dependent on the individual and tends to become consistent at fast walking.
More recently, Detrembleur [10] carried out a study on fifteen children from 4 to 11 years of age at different speeds ranging from 1.5 to $5.5 \mathrm{~km} / \mathrm{h}$. Findings, consistent with previous studies [11], demonstrated that the speed of progression is related to a change in the activation pattern of the Triceps Surae, the Peroneus Longus and the Tibialis Anterior.

EMG signals were also found to be strongly affected by speed in terms of amplification of peak values with increasing speed by Schwartz et al. [13]. Main changes reported were relative to the Medial Hamstrings activity at foot contact linearly increasing with speed, to the Rectus Femoris activity in early swing which changed from a plateau at very low speed to a peak of activation at high speed, to the activity of the Tibialis Anterior linearly increasing at higher speeds at early stance-phase and early swing phase.

\section{CONCLUSIONS}

There is large evidence on the advantages introduced by the use of EMG in the understanding of gait kinesiology, in

Table 1. Summary of Methodologies Used by Different Authors Cited in this Review

\begin{tabular}{|c|c|c|c|c|}
\hline & Material & Methods & EMG Changes Induced by Speed & EMG Changes Induced by Age \\
\hline $\begin{array}{l}\text { Sutherland } \\
\text { DH, } 1980\end{array}$ & $\begin{array}{l}19-44 \text { children } \\
\text { grouped according } \\
\text { to age from } 1 \text { to } 7 \\
\text { years }\end{array}$ & $\begin{array}{l}\text { Surface electrodes. Gluteus Medius, } \\
\text { Gluteus Maximum, Vastus Lateralis, } \\
\text { Vastus Medialis, Lateral and Medial } \\
\text { Hamstrings, Gastrocnemius-Soleus, } \\
\text { Tibialis Anterior. Timing of muscular } \\
\text { activity. }\end{array}$ & & $\begin{array}{l}\text { Shortening of phase of activity of } \\
\text { Gluteus Maximum (swing), } \\
\text { Vastus Medialis (stance and } \\
\text { swing), Tibialis Anterior (stance), } \\
\text { Medial and Lateral Hamstrings } \\
\text { (stance). Immature pattern of } \\
\text { Gastrocnemius-Soleus up to two } \\
\text { years. }\end{array}$ \\
\hline $\begin{array}{c}\text { Shiavi R et al, } \\
1987\end{array}$ & $\begin{array}{l}15 \text { children aged } 4- \\
7 \text { years and } 15 \\
\text { children aged } 8-11 \\
\text { years, speed } 0.6- \\
\quad 1.58 \mathrm{~m} / \mathrm{s}\end{array}$ & $\begin{array}{l}\text { Miniature bipolar surface electrodes } \\
\text { (Beckman). Rectus femoris, Lateral } \\
\text { Hamstrings, Medial Gastrocnemius, } \\
\text { Soleus, Peroneus Longus, Tibialis } \\
\text { Anterior, Tibialis Posterior (fine-wire). } \\
\text { Linear envelope. }\end{array}$ & $\begin{array}{l}\text { The linear envelopes tend to become } \\
\text { more consistent as speed increases. }\end{array}$ & $\begin{array}{l}\text { In the span } 4-11 \text { years changes of } \\
\text { Rectus Femoris envelopes } \\
\text { magnitude and of Lateral } \\
\text { Hamstrings peak timing. }\end{array}$ \\
\hline $\begin{array}{l}\text { Detrembleur } \\
\mathrm{C} \text { et al, } 1997\end{array}$ & $\begin{array}{l}15 \text { children aged } 4- \\
11 \text { years, speed } 1.5 \text { - } \\
5.5 \mathrm{~km} / \mathrm{h}\end{array}$ & $\begin{array}{l}\text { Miniature bipolar surface electrodes } \\
\text { (Beckman). Tibialis Anterior, Triceps } \\
\text { Surae and Peroneus Longus. On-off } \\
\text { visual inspection on the Linear envelope. }\end{array}$ & $\begin{array}{l}\text { Speed significantly increases the } \\
\text { relative duration of EMG activity in } \\
\text { all the three muscles. }\end{array}$ & No change based on age. \\
\hline $\begin{array}{l}\text { Okamoto T et } \\
\text { al, } 2003\end{array}$ & $\begin{array}{l}1 \text { subject from } \\
\text { neonatal stepping ( } 3 \\
\text { weeks) to mature } \\
\text { walking ( } 7 \text { years) }\end{array}$ & $\begin{array}{c}\text { Silver surface electrodes coated with } \\
\text { silver chloride. Gluteus Maximum, } \\
\text { Rectus Femoris, Vastus Medialis, } \\
\text { Lateral Hamstrings, Lateral } \\
\text { Gastrocnemius, Tibialis Anterior. Raw } \\
\text { signal. }\end{array}$ & $\begin{array}{l}\text { Change from gross pattern of muscle } \\
\text { activation with co-contraction to } \\
\text { mature phasic activation in the first } \\
\text { three years. }\end{array}$ & \\
\hline $\begin{array}{l}\text { Chang WN et } \\
\text { al, } 2007\end{array}$ & $\begin{array}{l}87 \text { children aged } 3- \\
18 \text { years }\end{array}$ & $\begin{array}{c}\text { Surface pre-gelled electrodes. Rectus } \\
\text { Femoris, Lateral Hamstrings, Medial } \\
\text { Gastrocnemius, Soleus, Peroneus Brevis, } \\
\text { Tibialis Anterior. Active range of each } \\
\text { muscle determined by visual inspection } \\
\text { on the normal mean linear enveloped } \\
\text { curve normalized by maximal amplitude } \\
\text { in a multistep trial. }\end{array}$ & $\begin{array}{l}\text { No differences with adults. } 13 \% \text { of } \\
\text { variability in children, subject } \\
\text { specific and situation specific. }\end{array}$ & $\begin{array}{l}\text { No immature pattern of } \\
\text { Gastrocnemius-Soleus. }\end{array}$ \\
\hline $\begin{array}{l}\text { Schwartz MH } \\
\text { et al, } 2008\end{array}$ & $\begin{array}{l}83 \text { children aged } \\
10.5 \pm 3.5 \\
\text { dimensionless } \\
\text { walking speed } \\
0.039-0.915\end{array}$ & $\begin{array}{c}\text { Surface electrodes. Rectus Femoris, } \\
\text { Medial and Lateral Hamstrings, Tibialis } \\
\text { Anterior, Medial Gastrocnemius. Linear } \\
\text { envelope normalized by dynamic } \\
\text { maximum. }\end{array}$ & $\begin{array}{l}\text { EMG signals were strongly affected } \\
\text { by speed in terms of amplification of } \\
\text { peak values with increasing speed. }\end{array}$ & \\
\hline
\end{tabular}


planning functional orthopaedic interventions in $\mathrm{CP}$ and in stroke patients [2]. However references on physiological patterns of muscular activation in children are limited.

Possible errors in the signal recording and in its processing procedures are to take into account as well as the variability depending on the previously discussed subjective and objective features.

In Table $\mathbf{1}$ a summary of methodologies used by different authors cited in this review is reported. This variability in procedures for electrodes positioning, signal registration, signal processing and interpretation make results comparison very difficult and scarcely reliable.

The study of the EMG signal for clinical gait analysis essentially concerns the analysis of the envelope of the myoelectric signal and the detection of muscle intervals of activation during the gait cycle. The techniques for integrating, rectifying, and averaging the signal are numerous, and there are no shared criteria for managing technical problems (time constants, filter characteristics, number of repetitions for averaging) thus introducing possible methodological errors [18]. On the other hand, the study of intervals of muscular activation has been widely used for clinical purposes, but, also in this case, methods proposed in literature are generally unsatisfactory because they are based on an arbitrary choice of a threshold that discriminates background noise from the signal generated by active muscles. This results in questionable shapes of the estimated activation patterns. Recently, more sophisticated methods have been introduced, based on double-threshold statistical detection of activation intervals that are able to adapt to different signal-to-noise ratios and accomplish an adequate level of sensitivity and specificity [19]. Results on a wide sample of healthy school age children provide a reliable system of reference on muscular control of gait [20]. The identification of EMG patterns of activation during pathological gait in children necessitates to rely on a solid base of knowledge of the EMG variability in healthy subjects. Further studies through accurate techniques of signal detection and analysis are required to improve our understanding of muscle physiology, kinesiological anatomy and human control system in children, thus refining our treatment options.

\section{REFERENCES}

[1] Frigo C, Crenna P. Multichannel SEMG in clinical gait analysis: A review and state-of-the-art. Clin Biomech 2009; 24: 236-45.

[2] Sutherland DH. The evolution of clinical gait analysis part 1: kinesiological EMG. Gait Posture 2001; 14: 61-70.

[3] Romkes J, Hell AK, Brunner R. Changes in muscle activity in children with hemiplegic cerebral palsy while walking with and without ankle-foot orthoses. Gait Posture 2006; 24: 467-74.

[4] Fuller DA, Keenan MA, Esquenazi A, Whyte J, Mayer NH, FidlerSheppard R. The impact of instrumented gait analysis on surgical planning: treatment of spastic equinovarus deformity of the foot and ankle. Foot Ankle 2002; 23:738-43.

[5] Perry J. Gait analysis. Normal and pathological function. Thorofare: Slack Incorporated 1992.

[6] Winter DA. The Biomechanics and Motor Control of Human Gait: Normal, Elderly and Pathological. 2nd Eds. Waterloo Biomechanics 1991.

[7] Shiavi R, Bugle HJ, Limbird T. Electromyographic gait assessment, Part I: Adult EMG profiles and walking speed. J Rehabil Res Dev 1987; 24: 13-23.

[8] Chang WN, Lipton JS, Tsirikos A I, Miller F. Kinesiological surface electromyography in normal children: range of normal activity and pattern analysis. J Electromyogr Kinesiol 2007; 17(4): 437-45.

[9] Shiavi R, Green N, McFadyen B, Frazer M, Chen J. Normative childhood EMG gait patterns. J Orthop Res 1987; 5: 283-95.

[10] Detrembleur C, Willems P, Plaghki L. Does walking speed influence the time pattern of muscle activation in normal children? Dev Med Child Neurol 1997; 39(12): 803-7.

[11] Sutherland DH. The development of mature gait. J Bone Joint Surg Am 1980; 62: 336-53.

[12] Okamoto T, Okamoto K, Andrew PD. Electromyographic developmental changes in one individual from newborn stepping to mature walking. Gait Posture 2003; 17: 18-27.

[13] Schwartz MH, Rozumalski A, Trost J P. The effect of walking speed on the gait of typically developing children. J Biomech 2008; 41(8): 1639-50.

[14] Gage JR. The treatment of gait problems in Cerebral Palsy. Mc Keith Press 2004.

[15] Yang JF, Winter DA. Electromyographic amplitude normalization methods: improving their sensitivity as diagnostic tools in gait analysis. Arch Phys Med Rehabil 1984; 65(9): 517-21.

[16] Kadaba M, Ramakrishnan H K, Wootten ME, Gainey J, Gorton G, Cochran GV. Repeatability of kinematic, kinetic, and electromyographic data in normal adult gait. J Orthop Res 1989; 6: 849-60.

[17] Granata KP, Padua DA, Abel MF. Repeatability of surface EMG during gait in children. Gait Posture 2005; 22(4): 346-50

[18] Staude G, Flachenecker C, Daumer M, Wolf W. Onset detection in surface electromyographic signals: a systematic comparison of methods. EURASIP J Appl Signal Processing 2001; 2: 67-81.

[19] Bonato P, D'Alessio T, Knaflitz M. A statistical method for the measurement of muscle activation intervals from surface myoelectric signal during gait. IEEE Trans Biomed Eng 1998; 45: 287-99.

[20] Agostini V, Nascimbeni A, Gaffuri A, et al. Gait analysis of school-age children: EMG activation patterns. Gait Posture 2009; 30 (Suppl 1) S57. 